\title{
Prevalence of Peptic Ulcer Disease and Associated Factors Among Dyspeptic Patients At Endoscopy Unit, University of Gondar Hospital, Northwest Ethiopia
}

\section{Belete Assefa \\ University of Gondar \\ Abilo Tadesse \\ University of Gondar \\ Zinahebizu Abay \\ University of Gondar \\ Alula Abebe \\ University of Gondar \\ Tsebaot Tesfaye \\ University of Gondar \\ Melaku Tadesse \\ University of Gondar}

Ayenew Molla Lakew ( $\nabla$ mayenew15@gmail.com )

University of Gondar

\section{Research Article}

Keywords: Dyspepsia, Peptic ulcer disease, H. pylori, NSAIDs, Northwest Ethiopia

Posted Date: December 15th, 2021

DOI: https://doi.org/10.21203/rs.3.rs-1152130/v1

License: (c) (i) This work is licensed under a Creative Commons Attribution 4.0 International License.

Read Full License 


\section{Abstract}

Background: Dyspepsia is a common complaint in upper gastrointestinal disorders. It is described as predominant epigastric pain lasting for at least one month. Peptic Ulcer Disease (PUD) occurs in 5-15\% of patients with dyspepsia. Helicobacter pylori (H.pylori) infection and non-steroidal anti-inflammatory drugs (NSAIDs)/aspirin (ASA) use are widely known risk factors for PUD. This research article aimed to determine the prevalence of PUD and associated factors among dyspeptic patients at the endoscopy unit, University of Gondar hospital, Northwest Ethiopia.

Methods: A hospital-based cross-sectional study was conducted at University of Gondar hospital. A sample of 218 adults who presented with the complaint of dyspepsia, and underwent endoscopic evaluation were interviewed from June 1 to November 30, 2020. A consecutive sampling method was used to recruit the study subjects. Relevant clinical history was obtained from patients' medical records. Upper gastrointestinal endoscopy was used to confirm the presence of peptic ulcer disease. The Data were entered into EpiData version 4.6.0.2 and exported to SPSS version 20 for analysis. Logistic regression analysis was used to identify associated factors with the occurrence of PUD among dyspeptic patients. P-value $<0.05$ was used to declare a statistically significant association.

Results: A total of 218 dyspeptic patients who underwent upper gastrointestinal endoscopic evaluations were included in the study. The PUD was diagnosed in one-third of patients with dyspepsia. Dyspeptic patients with active $\mathrm{H}$. pylori infection (AOR=6.3, 95\%Cl: 2.96-13.38) and NSAIDs/ASA use (AOR=6.2, 95\%Cl: 2.93-13.36) were at higher risk of developing PUD.

Conclusion: The magnitude of active $\mathrm{H}$. pylori infection among symptomatic PUD patients was high. So then, a "test-and-treat" strategy is advised. Cautious use of NSAIDs/ASA is required as it is readily available over-the-counter.

\section{Background}

Dyspepsia is a common complaint in upper gastrointestinal disorders. It is described as predominant epigastric pain lasting for at least one month. It can be associated with abdominal fullness, bloating, nausea, early satiety and epigastric burning. Globally, dyspepsia occurs in $10-20 \%$ of adults, and accounts for $3 \%$ of medical office visits. Dyspepsia has an impact on quality of life of patients and expenses to the health care service $(1,2)$. Peptic ulcer disease (PUD) occurs in $5-15 \%$ of patients with dyspepsia $(3,4)$. Imbalances in defensive and aggressive factors play a role in gastroduodenal mucosal injuries $(3,4)$. Helicobacter pylori (H.pylori) infection and nonsteroidal antiinflammatory drugs (NSAIDs)/aspirin (ASA) use are the major components of aggressive factors (3-8). H. pylori is the most prevalent human pathogen, which establishes chronic infection. H. pylori is widely known to cause gastritis and peptic ulcer disease. Also, it is attributed to gastric cancer and gastric B-cell lymphoma (36). Use of NSAIDs is recognized to cause erosive gastritis and peptic ulcer disease. Its use is ubiquitous worldwide and has increased occurrence of PUD by 3-to-5 fold (7-9). Other less frequently implicated risk 
factors include genetics, stress, diet, alcohol and smoking $(10,11)$. This study aimed to determine the prevalence of peptic ulcer disease and associated factors among dyspeptic patients at the University of Gondar hospital, northwest Ethiopia.

\section{Methods}

\section{Study design and setting}

A hospital-based cross sectional study was conducted at the endoscopy unit, University of Gondar hospital between June 1, 2020 and November 30, 2020. The hospital is located in Northwest Ethiopia, which is $750 \mathrm{~km}$ away from the capital, Addis Ababa. The hospital had a catchment population of 5 million people. Endoscopy unit at University of Gondar hospital provides endoscopic services for patients with gastrointestinal disorders.

\section{Study population and study subjects}

All patients who underwent endoscopic evaluation at endoscopy unit, University of Gondar hospital were the study population. Adults 18 years or older who presented with a complaint of dyspepsia, and underwent endoscopic evaluation at the endoscopic unit, University of Gondar hospital during the study period were the study subjects. The sample size was calculated using a single population proportion formula with the assumption of $95 \%$ confidence level, $5 \%$ margin of error, and taking a $15 \%$ estimated proportion of peptic ulcer disease among dyspeptic patients. The estimated sample size was 218 and consecutive sampling method was used to recruit them. Adults 18 years or older who presented with a complaint of dyspepsia, and underwent endoscopic evaluation at the endoscopic unit during the study period were included in the study, while study subjects who were on antibiotics or PPI in the last three weeks, had alarm symptoms, had contraindication to endoscopy or refused to undergo endoscopic evaluation were excluded from the study.

\section{Study variables and data collection procedures}

The dependent variable for this study was Peptic Ulcer Disease (PUD), and the independent variables were socio-demographic characteristics (include age, gender, residence, marital status, and socioeconomic status), Clinical characteristics (include H. pylori infection, NSAIDs/ASA use, presence of co-morbidities) and Behavioral factors (include smoking and alcohol consumption)

Data were collected through an investigator administered pre-designed questionnaire. The questionnaire was prepared in English and translated into the local language (Amharic) for data collection, and then retranslated back to English while maintaining its consistency. Patients were interviewed to obtain sociodemographic data, and relevant clinical history was obtained from patients' medical records. Lidocaine $(2 \%)$ throat spray and IV midazolam $(2 \mathrm{mg} / \mathrm{ml})$ were used as local anesthetic and sedative agents, respectively, before the procedure. A flexible fiber optic endoscope (Olympus, GIF-H170) was used for the procedure. All endoscopic procedures were conducted by trained physicians (internists and surgeons). 
Diagnoses of endoscopic appearances were at the discretion of the endoscopist. Endoscopic findings were documented on endoscopy registry book and patients' medical records. Diagnosis of H. pylori infection was made using the H.pylori Ag Rapid Test CE (CTK Biotech) (13).

\section{Data management and analysis}

Data were entered into EpiData version 4.6.0.2 and exported to SPSS version 20 for analysis.

Categorical variables were reported as counts (percentages) and continuous variables as mean with standard deviation. The results were summarized by using frequency, tables and graphs. Bi-variate and multi-variate logistic regression models were constructed to identify independently associated factors with peptic ulcer disease among dyspeptic patients. Those variables with a P-value $<0.25$ in the bi-variate analysis were exported to multi-variate. The crude odds ratio (COR) and adjusted odds ratio (AOR) were reported. P-value $<0.05$ was used to declare a statistically significant association.

\section{Ethical considerations}

The research protocol complied with the Declaration of Helsinki and ethical clearance was obtained from the Institutional Review Board (IRB) of the College of Medicine and Health Sciences, University of Gondar (19/02/2020, IRB No. 1267/02/2020). Study subjects were recruited only after written informed consent was obtained. All data obtained were treated confidentially. Those patients who were found to have peptic ulcer disease among $\mathrm{H}$. pylori positive patients were taken care of as per the recommendation of 2017 ACG clinical guideline: Treatment of Helicobacter pylori infection (14).

\section{Definition of Terms}

Dyspepsia is predominant epigastric pain lasting for at least one month.

Peptic ulcer disease is a defect in the gastric or duodenal mucosa that extends through the muscularis mucosa layer of the wall.

Alarm symptoms are symptoms likely indicate serious gastrointestinal diseases including malignancy, such as intractable vomiting, dysphagia, anemia, weight loss, or hematemesis or melena.

The endoscopy unit is a dedicated place in the University of Gondar hospital where endoscopic procedures are performed to visualize both upper and lower gastrointestinal structures. The procedures are performed by trained physicians (internists and surgeons) and the unit has additional staff members such as nurses and cleaners.

\section{Results}

\section{Socio-demographic characteristics of study subjects}


A total of 218 dyspeptic patients underwent upper gastro intestinal endoscopic evaluations were included in the study. The mean age of patients was 42 years ( \pm 16.3 SD). Among the study subjects, more than half $(54 \%)$ were males and urban dwellers (58\%). More than a third $(36 \%)$ had a history of alcohol consumption, while less than five percent $(4.6 \%)$ of them smoked cigarettes (Table- 1 ).

Table-1: Socio-demographic characteristics of dyspeptic patients, who underwent upper gastrointestinal endoscopic evaluation at endoscopy unit, University of Gondar hospital, June 1 to November 30, 2020

\begin{tabular}{|llll|}
\hline Characteristics & Category & Frequency & Percentage \\
\hline Age & $18-28$ & 59 & 27.1 \\
& $29-40$ & 56 & 25.7 \\
& $41-55$ & 51 & 23.4 \\
& $56+$ & 52 & 23.8 \\
\hline Sex & Male & 118 & 54.1 \\
& Female & 100 & 45.9 \\
& Single & 58 & 26.6 \\
& Married & 139 & 63.8 \\
& Divorced & 14 & 6.4 \\
& Widowed & 7 & 3.2 \\
\hline Residence & Urban & 126 & 57.8 \\
& Rural & 92 & 42.2 \\
& Orthodox Christian & 186 & 85.2 \\
& Protestant Christian & 7 & 3.2 \\
\hline Level of Education & Muslim & 25 & 11.6 \\
& Didn't join school & 72 & 33.1 \\
& Elementary school & 44 & 20.2 \\
& Secondary school & 40 & 18.3 \\
& College graduate & 31 & 14.2 \\
& Degree graduate and above & 31 & 14.2 \\
\hline
\end{tabular}

\section{Clinical characteristics of study subjects}

\section{Endoscopic findings}


Peptic ulcer disease (PUD) was diagnosed in one-third (35\%) of patients with dyspepsia. Two-thirds (72\%) of PUD cases had duodenal ulcers. Other organic causes of dyspepsia were gastritis/doudenitis (19\%), gastric mass (6\%) and pyloric obstruction (4\%). About one-third (36\%) had functional dyspepsia (Figure-1).

\section{H. pylori infection rate}

Half (49\%) of dyspeptic patients had active H. pylori infection. Two-thirds $(71.1 \%)$ of PUD patients had active $\mathrm{H}$. pylori infection. The majority $(85 \%)$ of $\mathrm{H}$. pylori infections among PUD cases had duodenal ulcer.

\section{NSAIDs/ASA users}

NSAIDs/ASA were used by forty percent (39.5\%) of dyspeptic patients. More than half $(54.7 \%)$ of NSAIDs/ASA users were diagnosed to have PUD.

\section{Co-morbidities}

One-third (29\%) had co-morbidities, including cardiovascular diseases, rheumatologic diseases, chronic airway diseases, and HIV infection.

\section{Factors associated with risk of developing PUD among dyspeptic patients}

Multivariable logistic regression analysis revealed dyspeptic patients with active $\mathrm{H}$. pylori infection and NSAIDs/ASA use were at risk of developing PUD, while unmarried study subjects were protected from developing PUD (Table-2).

Table-2: Bi-variable and multi-variable regression analysis of factors associated with peptic ulcer disease in upper gastrointestinal endoscopy evaluated dyspeptic patients at endoscopy unit, University of Gondar hospital, northwest Ethiopia, June 1 to November 30, 2020 


\begin{tabular}{|c|c|c|c|c|c|}
\hline \multirow[t]{2}{*}{ Variables } & & \multicolumn{2}{|l|}{ PUD } & \multirow[t]{2}{*}{$\operatorname{COR}(\mathrm{Cl})$} & \multirow[t]{2}{*}{ AOR (Cl) } \\
\hline & & Yes & No & & \\
\hline \multirow[t]{4}{*}{ Age } & $18-28$ & 19 & 40 & 1 & 1 \\
\hline & $29-40$ & 20 & 36 & $0.897(0.407-1.978)$ & $0.416(0.143-1.209)$ \\
\hline & $41-55$ & 19 & 32 & $1.049(0.476-2.314)$ & $0.796(0.274-2.309)$ \\
\hline & +55 & 18 & 34 & $1.122(0.501-2.509)$ & $0.542(0.178-1.670)$ \\
\hline \multirow[t]{2}{*}{ Sex } & Male & 44 & 74 & $0.791(0.451-1.388)$ & $1.406(0.702-2.817)$ \\
\hline & Female & 32 & 68 & 1 & 1 \\
\hline \multirow[t]{2}{*}{ Residence } & Urban & 45 & 81 & $1.093(0.621-1.924)$ & $0.739(0.368-1.484)$ \\
\hline & Rural & 31 & 61 & 1 & 1 \\
\hline \multirow[t]{2}{*}{ Marital Status } & Unmarried & 20 & 59 & $0.502(0.273-0.925)$ & $0.367(0.154-0.887)^{*}$ \\
\hline & Married & 56 & 83 & 1 & 1 \\
\hline \multirow[t]{2}{*}{ Alcohol drinking } & Yes & 24 & 54 & $0.752(0.417-1.358)$ & $0.488(0.227-1.047)$ \\
\hline & No & 52 & 88 & 1 & 1 \\
\hline \multirow[t]{2}{*}{ Cigarettes smoking } & Yes & 6 & 4 & $2.957(0.808-10.823)$ & $3.153(0.585-16.998)$ \\
\hline & No & 70 & 138 & 1 & 1 \\
\hline \multirow[t]{2}{*}{ Co morbidity } & Yes & 13 & 30 & $0.770(0.375-1.583)$ & $0.721(0.276-1.881)$ \\
\hline & No & 63 & 112 & 1 & 1 \\
\hline \multirow[t]{2}{*}{ H-Pylori infection } & Positive & 54 & 53 & $4.122(2.259-7.519)$ & $6.298(2.965-13.378)^{*}$ \\
\hline & Negative & 22 & 89 & 1 & 1 \\
\hline \multirow[t]{2}{*}{ NSAIDS/ASA use } & Yes & 47 & 39 & $4.280(2.369-7.734)$ & $6.252(2.925-13.362)$ \\
\hline & No & 29 & 103 & 1 & 1 \\
\hline
\end{tabular}

Dyspeptic patients with active $\mathrm{H}$. pylori infection had six times higher odds of having PUD compared with their counter facts (AOR=6.3, 95\% Cl: 2.96-13.38). Patients who used NSAIDs/ASA had also six times higher of PUD compared with those who did not $(A O R=6.25,95 \% \mathrm{Cl}$ : 2.92-13.3. Unmarried individuals reduced the odds of developing PUD by $63.3 \%(A O R=0.367, \mathrm{Cl}=0.15-0.89)$.

\section{Discussion}


Among a total of 218 dyspeptic patients, active H. pylori infection was documented in half (49\%) of study subjects. Likewise, the $\mathrm{H}$. pylori infection rate among PUD patients was $71 \%$. These findings were congruent with hospital-based sub-Saharan African (SSA) reports. The African reports verified that $40-$ $65 \%$ of dyspeptic and $60-90 \%$ PUD patients were positive for $\mathrm{H}$. pylori infection (16-19). The Ethiopian pooled prevalence of $\mathrm{H}$. pylori infection was $52 \%$ in a recent hospital-based meta-analysis (20). The global magnitude of $\mathrm{H}$. pylori infection was 34\% in Western Europe, 37\% in Northern America, and $70 \%$ in Africa (12). The global difference in the magnitude of the $\mathrm{H}$. pylori infection rate could be explained by the difference in socio-economic status, environmental sanitation, living conditions, and personal hygiene. In this study, PUD (35\%) was the commonly observed abnormal endoscopic lesion, followed by gastritis/duodenitis (19\%) and gastric mass (6\%). A Ghanaian study reported that PUD (54\%) followed by gastric cancer (12\%) were the most frequently detected endoscopic findings. While studies in Tanzania, Nigeria and Kenya witnessed gastritis (61-86\%) followed by PUD (14-24\%) were the commonly observed endoscopic pathologies. The difference in the type of gastroduodenal lesions among dyspeptic patients in African reports could be explained by differences in patient characteristics (age, genetics), H. pylori virulence strain, NSAIDs/ASA exposure rate, lifestyle preferences (smoking, alcohol), and other environmental factors (16-18). This study revealed that nearly forty percent (39\%) of dyspeptic patients had a history of NSAIDs/ASA use, and more than half (55\%) of NSAIDs/ASA users developed PUD. Western literature reviews documented that dyspepsia occurred in up to half (50-60\%) of patients taking NSAIDs/ASA, and up to a third (15-30\%) of patients using NSAIDs/ASA developed PUD (7-9). On multivariable logistic regression analysis, odds of developing PUD was 6 fold higher among dyspeptic patients with $\mathrm{H}$. pylori infection than those with negative $\mathrm{H}$. pylori infections (AOR=6.298, 95\% Cl: 2.965 13.378). It was confirmed that $\mathrm{H}$. pylori establishes prolonged gastro duodenal mucosal infection, and leads to chronic active gastritis and PUD (3-6, 16-19). Dyspeptic patients who use NSAIDs/ASA had 6 fold increased risk of developing PUD compared to non-NSAIDS/ASA users (AOR=6.252, 95\%Cl: 2.92513.362). NSAIDs/ASA interfere with the cyclo-oxygenase (COX) pathway and deplete biosynthesis of gastric prostaglandins. In addition, NSAIDS/ASA are weak acids which cause direct gastric mucosal toxic injury $(3,4,7-11)$. Study subjects with unmarried status were $60 \%$ protected from developing PUD as compared to their counter parts ( $\mathrm{AOR}=0.367,95 \% \mathrm{Cl}=0.154-0.887$ ). Reduced family size and non-crowded living condition among unmarried subjects might contribute to reduced $\mathrm{H}$. pylori infection rate and occurrence of PUD.

\section{Strength And Limitation Of The Study}

The major strength of this study was its prospective study design, which allowed collecting reliable data. The limitation of the study was selection bias as referred patients with dyspepsia were included.

\section{Conclusions}

Peptic ulcer disease (PUD) was diagnosed in one-third of patients with dyspepsia. Two-thirds of PUD patients had active $\mathrm{H}$. pylori infection. NSAIDs/ASA were used by forty percent of dyspeptic patients. Half 
of NSAIDs/ASA users were diagnosed to have PUD. Dyspeptic patients with active H. pylori infection and NSAIDs/ASA use were at risk of developing PUD. The magnitude of active $\mathrm{H}$. pylori infection among symptomatic PUD patients was high. So then, a 'test-and-treat' strategy is advised. Cautious use of NSAIDs/ASA is required as it is readily available over-the-counter.

\section{Abbreviations}

ACG: American College of Gasrtoenterology; ASA: Aspirin; AOR: Adjusted Odds Ratio; Cl; Confidence Interval; COR: Crude Odds Ratio, H.pylori, Helicobacter pylori, IV: Intravenous; NSAIDs, Nonsteroidal Antiinflammatory Drugs; PPI: Proton Pump Inhibitors; PUD: Peptic Ulcer Disease

\section{Declarations}

\section{Ethics approval and consent to participate}

The study was performed in accordance with the Declaration of Helsinki and approved by the Institutional Review Board of College of Medicine and Health Sciences, University of Gondar (19/02/2020, IRB No. 1267/02/2020). Written informed consents for participation were obtained from study subjects or their caregivers.

\section{Consent for publication}

Written informed consent for publication was obtained from study subjects.

\section{Availability of data and materials}

All data generated and analyzed were included in this research article.

\section{Funding}

Funding for research was obtained from the 'Research and Publication Office' of the College of Medicine and Health Sciences, University of Gondar. The funding body had no role in the design of the study, data collection, analysis and interpretation of the data.

\section{Acknowledgements}

We are grateful to thank the study participants and their health personnel.

\section{Authors' contributions}

Belete Assefa contributed to the conception, design, data collection, analysis, writing, and review of the manuscript. Abilo Tadesse contributed to the conception, design, analysis, writing and review of the manuscript. Zenahbizu Abay, Alula Abebe, Tsebaot Tesfaye, Melaku Tadesse and Ayenew Molla 
contributed to conception, design, analysis and review of the manuscript. All authors read and approved the final manuscript and approved its submission for publication.

\section{Competing interests}

The authors declare that they have no competing interests.

\section{References}

1. Moayyedi PM, Lacy BE, Andrews CN, Enns RA, Howden CW, Vakil N. ACG and CAG clinical guideline: Management of dyspepsia. Am J Gastroenterol 2017;112:988-1013.

2. Stanghellini V, Chan FKL, Hasler WL, Malagelada JR, Suzuki H, Tack J, et al. Gastrointestinal disorders. Gastroenterol 2016;150: 1380-92.

3. Malfertheiner P, Chan FKL, McColl KEL. Peptic ulcer disease. Lancet. 2009; 374:1449-61.

4. Kevitt RT, Lipowska AM, Anyane-Yebou A. Diagnosis and treatment of peptic ulcer disease. AM J Med 2019; 132(4):447-56.

5. Mc Coll KEL. Helicobacter pylori infection. N Engl J Med 2010; 362: 1597-604.

6. Mladenova I. Clinical relevance of Helicobacer pylori infection. J Clin Med 2021;10: 3473-84.

7. Russell RI. Non-steroidal anti-inflammatory drugs and gastrointestinal damage-problems and solutions. Postgrad Med J 2001;77: 82-88.

8. Rodriguez LAG, Hernandez-Diaz S. Risk of uncomplicated peptic ulcer among users of aspirin and non-aspirin non-steroidal anti-inflammatory drugs. Am J Epidemiol 2004;159(1):23-31.

9. Frech EJ, Go MF. Treatment and chemoprevention of NSAID-associated gastrointestinal complications. Therap Clin Risk Manag 2009;5:65-73.

10. Lee SP, Sung I-K, Kim JH, Lee S-Y, Park HS, Shim CS. Risk factors for the presence of symptoms in peptic ulcer disease. Clin Endosc 2017;50:578-84.

11. Asal AM, Alghamdi MA, Fallatah SA, Alholaily WA, Aldandan RG, Alnosair AH, et al. Risk factors leading to peptic ulcer disease: Systematic review in literature. Int $\mathrm{J}$ Community Med Public Health 2018;5(10):1-8.

12. Hooi JKY, Lai WY, Ng WK, Suen MM, Underwood FE, Tanyingoh D, et al. Global prevalence of Helicobacter pylori infection: Systematic review and meta-analysis. Gastroenterol 2017;153:420-29.

13. Shimoyama T. Stool antigen tests for the management of Helicobacter pylori infection. World J gastroenterol 2013;19(5):8188-91.

14. William C, Grigorios L, Colin H, Steven M. ACG clinical guideline: Treatment of Helicobacter pylori infection. American J Gastroenterol 2017;112(2):212-39

15. Archampong TN, Asmah RH, Richards CJ, Martin VJ, Bayliss CD, Batao E, et al. Gastro-duodenal disease in Africa: Literature review and clinical data from Accra, Ghana. World j Gastroenterol 2019;25(26):3344-58. 
16. Archampong TNA, Asmah RH, Wiredu EK, Gyasi RK, Nkrumah KN. Factors associated with gastroduodenal disease in patients undergoing upper GI endoscopy at the Korle-Bu Teaching hospital, Accra, Ghana. Afric Health sci 2016;16(2):611-20.

17. Jemilohun AC, Otegbayo JA, Ola SO, Oluwasola OA, Akere A. Prevalence of Helicobacter pylori among Nigerian patients with dyspepsia in Ibadan. Pan Afric Med J 2011;6:18-16.

18. Ayana SM, Swai B, Maro VP, Kibiki GS. Upper gastrointestinal endoscopic findings and prevalence of Helicobacter pylori infection among adult patients with dyspepsia in northern Tanzania. Tanzania J Health Res 2014;16(1):1-9.

19. Mwangi CN, Njoroge S, Rajula A, Laving A, Kamenwa R, Devani S, et al. Prevalence and endoscopic finding s of Helicobacter pylori infection among dyspeptic patients in Kenya. Open J Med Microbiol 2020;10:233-42.

20. Melese A, Genet C, Zeleke B, Andualem T. Helicobacter pylori infections in Ethiopia; prevalence and associated factors: a systematic review and meta-analysis. BMC Gastroenterol 2019;19(8):1-15.

\section{Figures}

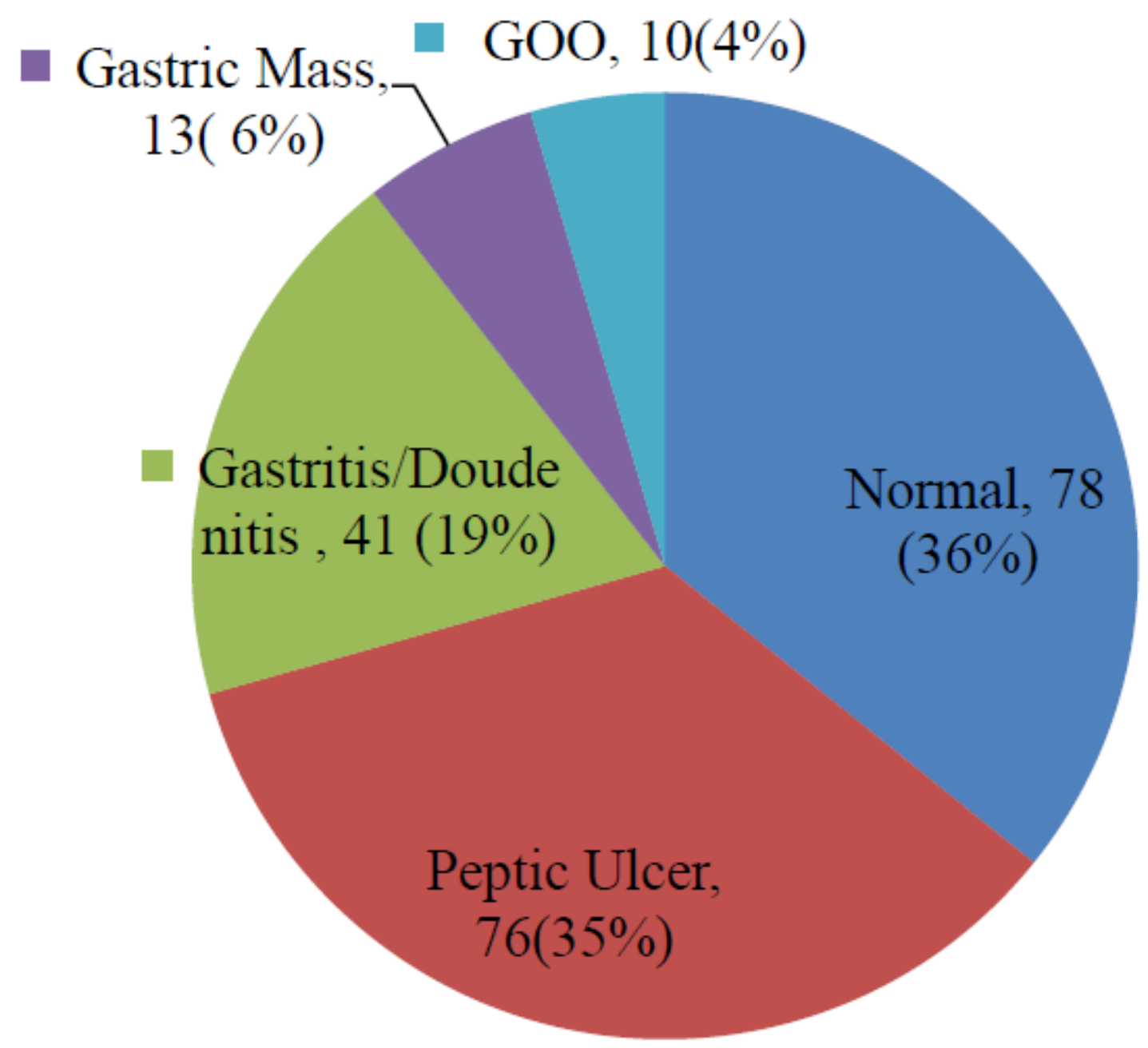


Endoscopic findings among patients with dyspepsia University of Gondar hospital, 2020 